\title{
PELLAGRA IN AN ENGLISH CHILD
}

\author{
BY \\ G. W. HICKISH \\ From Odstock Hospital, Salisbury
}

(RECEIVED FOR PUBLICATION AUGUST 28, 1954)

Pellagra is very rare in this country except for occasional mild cases amongst elderly inmates of mental institutions (Hardwick, 1943). No case has been reported in a child since 1940, when Hope Simpson (1940) described the condition in an English schoolgirl aged 11 years, in whom the outcome was fatal.

A case of pellagra in a young child, due to an unusually fastidious appetite, is described below.

\section{Case Report}

In September, 1953, a girl aged 4 years and 9 months was admitted to hospital suffering from extreme weakness, a rash and mental confusion. In June, 1953, the commonest month, according to Goldberger, Wheeler, Sydenstricker and King (1929), for the onset of pellagra, her parents first noticed an erythematous rash on the cheeks and chin, quickly followed by a similar rash on the exposed parts of the arms and legs. The rash was persistent and noticeably worse after exposure to sunlight.

Soon after the development of the rash, she began to complain of attacks of dizziness, which recurred with increasing frequency in the ensuing weeks.

During the three weeks before admission, she became increasingly weak and spent most of her time either in bed or lying on a settee, unable to stand up for more than a few minutes.

Since June there had been a progressive loss of appetite and a loss of weight of $9 \mathrm{lb}$. There had been no vomiting or diarrhoea. There was a tendency to constipation. A little frequency of micturition occurred in the week preceding admission.

The patient lived with her parents and grandmother, all of whom enjoyed good health. An only child, she had never had a big appetite and since the age of 1 year she had refused to eat cereals, meat and all green vegetables.

A typical day's diet the previous winter had been:

\begin{tabular}{ll} 
Breakfast: & $\begin{array}{l}\text { Boiled egg, bread and butter, tea. } \\
\text { Lunch: }\end{array}$ \\
& $\begin{array}{l}\text { Potatoes and gravy, occasionally } \\
\text { carrots, fruit and custard or rice } \\
\text { pudding. }\end{array}$ \\
Tea: & $\begin{array}{l}\text { Bread and butter, cake, tea. } \\
\text { Supper: }\end{array}$ \\
\hline
\end{tabular}

Occasional extras were bananas, grapes, oranges, sweets, milk chocolate.

Virol, three teaspoonfuls daily, was given from November until March.

Her diet on the day before admission was:

Breakfast: One slice buttered toast, 1 cup milky tea.

Mid-morning: One tablespoonful of milk jelly.

Lunch: One small potato, gravy made from meat, 1 tablespoonful of grated carrot, 1 dessertspoonful of stewed apple, small portion of custard.

Tea: One small teacake with butter, 1 cup milky tea.

Supper: One cup of milk, 1 biscuit.

On admission, the patient was tall and thin (height $3 \mathrm{ft} .8$ in., weight 2 st. $3 \frac{1}{2} \mathrm{lb}$.).

Her skin was strikingly dry. A darkly pigmented, thickened and hyperkeratotic condition was present, chiefly on the exposed areas. On the limbs, the affected areas followed a symmetrical 'stocking' and 'long glove' distribution. Isolated, similar patches were present on the buttocks. On the face, the distribution was of 'butterfly' type on the cheeks and dorsum of the nose and the sides of the chin were also affected. The neck was relatively unaffected.

The tongue was bright red, smooth and clean, with ukcers on the under-surface. The buccal mucous membrane was also bright

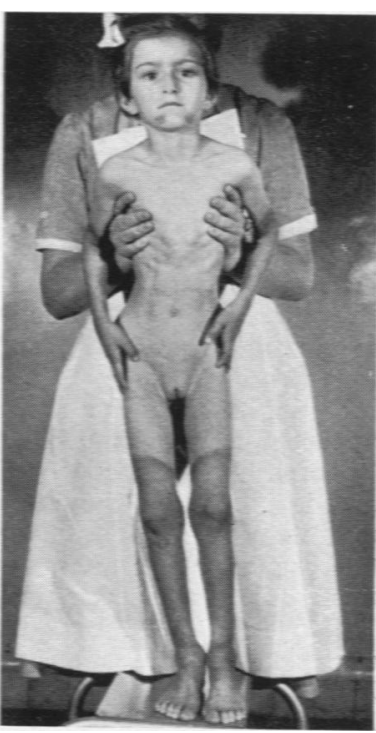

FiG. 1. red. No cheilosis was present. The teeth were sound.

The pulse rate varied from 100 to 145 per minute with normal rhythm. The apex beat was normal in position and the heart sounds were normal. 


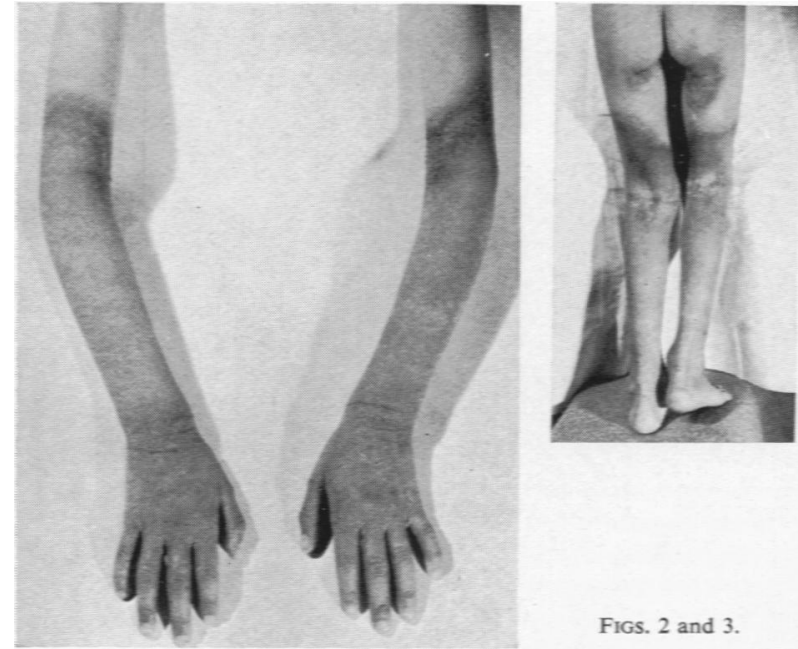

Clinical examination of the lungs and abdomen showed no abnormality.

Tactile sense was impaired over the cutaneous lesions of the limbs, normal elsewhere. All tendon reflexes were sluggish but symmetrical. The abdominal reflexes were normal. Coordination was unimpaired. The cranial nerves were intact and the optic fundi normal. The child was cooperative but easily tired, with a poor faculty for concentration.

The blood picture and E.S.R. were normal. Serum protein was 6.0 g. $\%$ (albumin $4.4 \mathrm{~g}$. \%, globulin 1.6 g. \%). Blood chemistry was otherwise normal.

The urine contained no albumin, but a little sugar $(0.3 \%)$ was present, with some acetone. Phenyl pyruvic acid and porphyrins were absent from the urine.

Radiographs of the chest and wrists were normal. The electrocardiogram was normal.

The diagnosis of pellagra was made and treatment was begun with nicotinamide, $25 \mathrm{mg}$., three times daily by mouth. This was increased to seven times daily the following day. In addition, 'becosym', $2 \mathrm{ml}$. daily, was injected intramuscularly, and two 'adexolin' capsules were also given daily.

During the following few days intermittent diarrhoea and intermittent glycosuria (0.3\%) occurred. According to Bicknell and Prescott (1953), impaired glucose tolerance is a regular finding in pellagra. Glucose tolerance tests were carried out and showed impaired tolerance. Glycosuria ceased after two weeks, and a glucose tolerance test after three weeks gave a normal result.

Two days after the start of treatment mild mental confusion persisted but an improvement in the cutaneous lesions was already noticeable. The knee jerks were found to be slightly exaggerated and ankle clonus was elicited.

A week later, the patient's appetite had definitely improved and the patient, with encouragement, was also eating a little meat. After 12 days, oral 'becosym', $5 \mathrm{ml}$., was substituted for the parenteral dose.

Three weeks after the start of treatment all diarrhoea had ceased. However, the patient remained a little disorientated, her appetite began to deteriorate again, and by October 26 her weight, which had risen by $2 \frac{1}{2}$ lb., had fallen back to the weight recorded on admission. There followed a period of three weeks during which weight remained stationary and appetite varied greatly from day to day. There was, however, no relapse of the dermatitis, which progressively dwindled.

Two months after admission, in an attempt to induce appetite, soluble insulin was administered 20 minutes before meals, starting with 2 units and gradually increasing the dose. A slight improvement in appetite followed and weight began very slowly to increase. Eight units gave the maximal benefit, but 10 units caused a hypoglycaemic reaction.

The patient was discharged from hospital at the end of January, active and symptom-free, but she had gained only $3 \mathrm{lb}$. in weight since admission. She was last seen on July 15, 1954, when she had gained a further $9 \mathrm{lb} .14 \mathrm{oz}$. She was eating a normal diet, supplemented by two 'multivite' tablets daily and was enjoying excellent health. The skin was normal.

\section{Discussion}

The Nutrition Committee of the British Medical Association (1950) suggested $6 \mathrm{mg}$. as the daily requirement of nicotinic acid at this age. Analysis of the patient's recent diet shows a total daily content in the neighbourhood of only $1 \mathrm{mg}$.

Ten years ago nicotinic acid itself was used in the treatment of pellagra. Nicotinamide is now preferred as it does not have the vasodilatory and other undesirable effects of the former substance. The dosage is the same, and Bicknell and Prescott (1953) suggest a dose of 300 to $500 \mathrm{mg}$. daily in a severe adult case.

In the present case, treatment produced only a temporary increase in appetite and real improvement did not begin until meals were preceded by insulin. This was used with caution, for pellagrins are believed to be hypersensitive to insulin, suffering hypoglycaemic reactions more readily than normal persons (Mainzer, 1949).

\section{Summary}

A case of pellagra in an English child of preschool age is described.

I have to thank Dr. D. W. Beynon for permission to publish this case, and Mr. J. Clark for photographs.

\section{REFERENCES}

Bicknell, F. and Prescott, F. (1953). The Vitamins in Medicine, 3rd ed., p. 358 . London.

Goldberger, J., Wheeler, G. A., Sydenstricker, E. and King, W. I. (1929)." A Study of Endemic Pellagra in some Cotton-mill (1929). A Study of Endemic Pellagra in some Cotton-mill Villages of South Carolina. Hygienic Laboratory Bulleti
No. 153. U.S. Public Health Service, Washington, D.C. Hardwick, S. W. (1943). Lancet, 2, 43.

Mainzer, F. (1949). Trans. roy. Soc. trop. Med. Hyg., 43, 329.

Simpson, R. E. Hope (1940). Lancet, 2, 589. 